\title{
Research on Industrial Talent Effectiveness in Beijing Region-Enterprise-Level Data Based on Secondary and Tertiary Industries
}

\author{
Wu Jianning ${ }^{1}$, Qu Xiaofei ${ }^{1} \&$ Wang Xuanhua ${ }^{2}$ \\ ${ }^{1}$ Department of Management and Economics of Dalian University of Technology, Liaoning, China \\ ${ }^{2}$ Postdoctoral Workstation of Chinese Academy of Personnel Science, Beijing, China \\ Correspondence: Wu Jianning, Department of Management and Economics of Dalian University of Technology, \\ Liaoning, China. E-mail: wujn@neusoft.com
}

\author{
Received: December 14, 2012 Accepted: January 28, 2013 Online Published: February 20, 2013 \\ doi:10.5539/ijbm.v8n6p55 \\ URL: http://dx.doi.org/10.5539/ijbm.v8n6p55
}

\begin{abstract}
The paper measures talent performance by decomposing the enterprise income of the secondary and tertiary industries, and comparing talent effectiveness in 17 areas with Principal Component Analysis, and reveals that either within the secondary and tertiary industries, or in a comprehensive comparison of the two types of industry, the talent effectiveness of the urban central areas with relatively high economy levels gives a better performance, while well-educated talents perform better in suburbs (counties) than in the urban central areas. Under such kind of circumstances, an urban and rural talent integration policy is being studied and analyzed by Beijing bureau currently to contribute a more balanced distribution of talents. This essay could be referred to as the reference resources or guidance for different level of bureaus.
\end{abstract}

Keywords: industry talents, talent effectiveness, talent structure, excessive concentration

\section{Introduction}

As the theory of Neo-Classical Economic Growth states, the factors that boost economic growth include physical capital, human capital, as well as science and technology. Due to the existence of overflow, investment in human capital has undoubtedly been experiencing increasing returns to scale (Lucas, 1988). Human capital is also a contributing factor to the growth of national economy, and population quality and investment in knowledge greatly determine the future of human being (Schultz, 1960). Education is the main way of accumulation for human capital (Schultz, 1961). And talent capital is the high-ranking section of human capital (Note 1). The accumulation and effectiveness of human capital plays a vital role in changing the pattern of economic growth. Based on the empirical research, the regional distribution of Chinese talent capital has been experiencing the state of imbalance for a long time: the talent capital in eastern coastal regions is relatively abundant, while that of central and western regions is relatively deficient (Anming, Chen 2007). And T. Cai (2012) pointed out that the similarities of regional industrial structure tend to cause the problem of talent shortage. Meanwhile, according to L. Jiang, the structural distribution of talent structures in different regions influences the development of technology. Beijing Region is one of the most intensive regions for talent capital in China, in which the overall qualities of talents take the lead in the nationwide. In 2011, the percentage of the employees who have received higher education amounts to $39 \%$, which is nearly $11 \%$ higher than that of Shanghai----the second most intensive regions for talent capital in China (Note 2). The talents in Beijing include nearly 700 academicians of the Chinese Academy of Sciences and Chinese Academy of Engineering, more than 400 overseas high-level talents who are chosen in the central-government "Thousand Talents Program" and more than 300 overseas high-level talents who are chosen in Beijing "Overseas Talents Aggregation Program" (Note 3). How to measure the performance of the talents in economic activities has always been a topic for talent management department and a debated issue in academic circles. Researchers in China have made some progress on evaluating the talents performance on economic activities, such as the measures of Talent Effectiveness (Pan Chenguang, 2004; Wang Xuanhua, etc., 2010, 2011b, 2012) and Talent Contribution Rate (Gui Zhaoming, 2009; Wang Xuanhua, etc., 2011a). Talent effectiveness is a negative index, which takes talent as a production cost factor from the perspective of input, and presents it with the output of unit talent. If the value is low, it means that it costs 
relatively low to achieve certain economic accomplishment, and that the productivity is relatively high. Talent Contribution Rate is a positive index to investigate the degrees of talent effect from the perspective of output, which reflects the portion of contribution from talents in the economic growth. If the value is high, it means that talents play an important role in the economic activities, and that the newly-added talents contribute more in the economic growth. The two measures have their own advantages and disadvantages. The Talent Effectiveness is relatively easier to measure, understand, and operate, whilst Talent Contribution Rate needs relatively longer time series data or panel data, and the output elasticity measured with production function is more difficult for unprofessional staff to understand. Besides, the results of the calculation lack stability, which are difficult for researchers to agree on for they may be greatly different with different researchers. Therefore, we adopt the Talent Effectiveness to measure the degrees of effect talents (Note 4). We take the secondary and tertiary industries in 17 areas of Beijing as the research objects (Note 5), and compare the effects of talents among different areas with Principal Component Analysis. The analysis framework can be divided into 4 parts: Part 1 is to introduce the present study from home and abroad about the effect of talents on economic activities. Part 2 is to discuss the measuring method of Talent Effectiveness. Part 3 is to measure the Talent Effectiveness in different areas and compare the differences among areas. Part 4 is to analyze the results of comparison and propose solutions to the problem.

\section{Literature Review}

Many researchers have been studying on the economic contributions of human capital for a long time. For example, Schultz compared investment in human capital with investment in other factors, and found the return of the former is higher than the latter according to his research on the relationship between American educational investment and economic growth from 1929 to 1957. From his research, American "Education Capital" inventory for labors amounted to USD535 billion in 1957 from USD180 billion in1930, and 20\% of economic growth come from the increase of the educational capital inventory in the same period. The rate of return for investment in education on different levels was $17 \%$ on average, and the rate of return for the increase of investment in education amounted to about $70 \%$ of the increase in labor income, which made up about $33 \%$ of national income increase (Schultz, 1961). Later on, Edward F. Denison obtained the similar result with a different measure, i.e., the contribution rate of education to American national income increase was $35.3 \%$ from 1929 to 1957 , and the contribution rate of the prolonged education for labors to national income per capita was 25\% from 1929 to 1982 (E. F. Denison, 1985). Robert J. Barro came to the conclusion that an important drive for GDP growth was human capital by comparing the GDP increase data per capita of 98 countries from 1960 to 1985 (Robert J. Barro, 1991). Donal O'Neill proved the differences of contribution rate of education to economic growth between developed countries and developing countries with time series data from 1967 to 1985 . The conclusion showed that contribution rate of education to economic growth in developed countries was $6 \%$ lower than that of developing countries. The former was $58 \%$, and the latter was $64 \%$ (Donal O'Neill, 1995). Therefore, it is concluded that there are long-term stable relationship and short-term coordination mechanisms between investment in education and economic growth.

In recent years, affected by Western research findings, some researchers in China began to pay attention to the problem of human capital efficacy, which was mainly concentrated on two aspects: one was to discuss the connotation of talent capital efficacy and try to find out the ways to improve Talent Effectiveness based on it ( $\mathrm{Li}$ Qun, etc., 2006); the other was to discuss the measures for talent capital efficacy (Li Haizheng, etc., 2010). From the former research, Talent Effectiveness refers to the degrees of effort that talents make in economic activities, and the effect is restricted by the talent scale and affected by the economic development of the area. At the micro level, the enterprise performance mainly relies on talent capital instead of fund, production equipment or workplace (Yang Bin, 2004). The competitiveness of an enterprise results in the social attributes of staff, which play an important role in promoting the talents to deliver their full potentials (Wang Ziqiang, etc., 2004). There are few specialty works about measures of Talent Effectiveness in China. In early researches, Talent Effectiveness was measured through the proportion of the input of factors in economic activities and the amount of output, which implied a hypothesis, i.e. factors of input only include human capital by ignoring the effect of physical capital, regulations and etc.(Note 6). In addition, the incremental data of economic activities are taken to measure output, which are mainly the total output value of an area. Therefore, the ways of measuring human capital are apparently different. For example, Pan Chenguang, etc. (2004), Chen Anming (2007) and Li Qun, etc. (2006) all take the number of human/talent capital to measure the input scale; Gui Zhaoming (2009), Wang Xiaolu, etc. (2010) and Wang Xuanhua, etc. $(2010,2011 \mathrm{a}, 2011 \mathrm{~b})$ take the years of education to measure the scale of human capital; and some researchers like Li Haizheng take Lifetime Income Method to measure human capital inventory. From the results of the researches, if researchers take different measures to measure the same 
sample, and get similar conclusion, that means the measures have a high reliability.

\section{Research Design}

\subsection{Measures for Talent Effectiveness}

Under the guidance of Input-Output Principle, we adopted the same measure as researchers like Pan Chenguang, etc. (2004), Chen Anming (2007), Li Qun, etc. (2006) and Wang Xuanhua, etc. (2010, 2011a, 2011b) (2006) did. The model is as following:

\section{Talent Effectiveness $\left(e_{i}\right)=$ Scale of Input Talents $\left(h_{i}\right) /$ Economic Output $\left(y_{i}\right)$}

In short: $e_{i}=h_{i} y_{i}$

In the model, $e_{i}$ refers to Area Talent Effectiveness No. $i, h_{i}$ refers to Scale of Input Talents No. $I$, and $y_{i}$ refers to Economic Output No. $i$. Therefore, the economic connotation of $e_{i}$ should be: the unit of variable $h_{i}$ is the cost of Talent Effectiveness numbers in the output of a unit; $y_{i}$ is in unit of "Million CNY", and the unit of $e_{i}$ should be person/ Million CNY.

\subsection{The Ranking of Talent Effectiveness in Different Areas}

According to the domestic Research Works, most researchers directly compare the economic output and investment in talent capital among different areas, like what Pan Chenguang, etc. (2004), Li Qun, etc. (2006) and Wang Xuanhua, etc. $(2010,2011 \mathrm{a}, 2011 \mathrm{~b})$ did. In their research, they did not consider the effect of talent structural distribution to the efficacy. Only a few researchers took talent structure into evaluation of Talent Effectiveness, like Pan Anming (2007). A comprehensive evaluation system comes into being by taking structure variable into efficacy model. In evaluating Talent Effectiveness, there will be a high probability for the system to provide overlapping information due to Multiple Colinearity of some indexes. This kind of problem is usually solved with Principal Component Analysis (PCA in short). PCA was originally introduced by Pearson in 1901, and further developed by Hotelling in 1933. The core idea of it is to realize the purpose of simplify analysis while containing most original variable information, by dividing multiple factors into several comprehensive factors with the way of Dimension Reduction.

As most indexes of Principal Component Analysis are positive, while Talent Effectiveness index is negative, the negative index is adjusted to positive index to meet the need of Principal Component Analysis. Since the effect of human talent structure is taken into consideration, the Talent Effectiveness Structures of different areas form the Talent Effectiveness Matrix $\left(E_{i}\right)$, i.e., $E_{i}=\left(1 / e_{i}\right)_{m \times n}=\left(y_{i} / f_{i}\right)_{m \times n}$.

\section{Result and Comparison of Talent Effectiveness Measurement}

\subsection{Talent Effectiveness of the Secondary Industry}

We have taken the second Economic Census Data of Beijing Area to make comparison and analyze the Talent Effectiveness data in 17 areas of Beijing Region. In measuring the Talent Effectiveness, we take the enterprise income of the secondary industry as the talent output, and focus the investigation on the relationship between the talent structure and economic efficacy.

We substitute the enterprise income and talent data into the Talent Effectiveness model to form the matrix, take the reciprocal, and get the Talent Effectiveness matrix values needed for evaluation. Talent Effectiveness Evaluation Matrix for the Second Industry in Beijing Area can be seen in Table II in the Appendix. Then we extract the principal component with Principal Component Analysis, and get the result as shown in Table 1.

Table 1. Principal component description of the talent economic efficacy of secondary industry in Beijing region

\begin{tabular}{cccc}
\hline Principal Component Eigenvalue & Contribution Rate of Variance & Accumulated Contribution Rate of Variance \\
\hline$F_{1}$ & 8.6473 & 0.6652 & 0.6652 \\
$F_{2}$ & 1.6880 & 0.1298 & 0.7950 \\
$F_{3}$ & 1.4865 & 0.1143 & 0.9094 \\
$F_{4}$ & 0.5244 & 0.0403 & 0.9497 \\
\hline
\end{tabular}

According to the basic principle of KPCA, principal components $F_{1}, F_{2}$ and $F_{3}$ in Table 1 are chosen for further analysis, which can be reflected more than $90 \%$ information of the 13 variants. The respective load of the 3 principal components is: 
Table 2. Principal component eigenvectors of talent economic efficacy in secondary industry

\begin{tabular}{cccc}
\hline Variants & $\mathrm{F}_{1}$ & $\mathrm{~F}_{2}$ & $\mathrm{~F}_{3}$ \\
\hline $\mathrm{X}_{01}{ }^{* *}$ & 0.138215 & 0.668929 & 0.030022 \\
$\mathrm{X}_{02}{ }^{* *}$ & 0.281999 & 0.370835 & -0.172716 \\
$\mathrm{X}_{03}{ }^{* *}$ & 0.321904 & 0.089351 & -0.210382 \\
$\mathrm{X}_{04}{ }^{* *}$ & 0.224107 & -0.00754 & -0.502905 \\
$\mathrm{X}_{05}{ }^{* *}$ & 0.289677 & -0.356036 & -0.164765 \\
$\mathrm{X}_{06}{ }^{* *}$ & 0.295567 & 0.274675 & 0.127192 \\
$\mathrm{X}_{07}{ }^{* *}$ & 0.333375 & 0.085927 & 0.019312 \\
$\mathrm{X}_{08}{ }^{* *}$ & 0.326615 & -0.101371 & -0.012471 \\
$\mathrm{X}_{09}{ }^{* *}$ & 0.301741 & -0.05064 & -0.041884 \\
$\mathrm{X}_{10}{ }^{* *}$ & 0.262398 & -0.008709 & 0.420675 \\
$\mathrm{X}_{11}{ }^{* *}$ & 0.152339 & -0.004925 & 0.641372 \\
$\mathrm{X}_{12}{ }^{* *}$ & 0.293316 & -0.278274 & 0.186473 \\
$\mathrm{X}_{13}{ }^{* *}$ & 0.298827 & -0.327118 & -0.05821 \\
\hline
\end{tabular}

According to Table 2, the loads of the first principal component to 11 variants are almost the same except for the relative small loads to $\mathrm{X}_{01}{ }^{* *}$ and $\mathrm{X}_{11}{ }^{* *}$, which means that $\mathrm{F}_{1}$ has reflected the Talent Effectiveness; the second principal component mainly reflects the Talent Effectiveness of talents with degrees of master or above. The third principal component reflects Talent Effectiveness of senior workers. We synthesize the three principal components and rank them with Contribution Rate of Variance as weight, and get the results as follows:

Table 3. Ranking on talent economic efficacy of second industry in Beijing region

\begin{tabular}{lcccccccc}
\hline & $\mathrm{F}_{1}$ & Ranking on $\mathrm{F}_{1}$ & $\mathrm{~F}_{2}$ & Ranking on $\mathrm{F}_{2}$ & $\mathrm{~F}_{3}$ & Ranking on $\mathrm{F}_{3}$ & $\mathrm{~F}$ & Overall Ranking on $\mathrm{F}$ \\
\hline Dongcheng Dis. -1.28 & 11 & -0.99 & 14 & -0.15 & 8 & -1.09 & 11 \\
Xicheng Dis. & 3.52 & 2 & -0.25 & 9 & -2.34 & 17 & 2.24 & 3 \\
Chaoyang Dis. & -2.42 & 14 & -0.99 & 15 & -0.47 & 12 & -1.97 & 14 \\
Fengtai Dis. & -2.01 & 12 & -0.67 & 13 & -0.67 & 14 & -1.65 & 13 \\
Shijingshan Dis. & 0.83 & 6 & 0.66 & 5 & -1.55 & 16 & 0.50 & 7 \\
Haidian Dis. & -0.82 & 9 & -1.82 & 16 & -0.23 & 10 & -0.89 & 10 \\
Fangshan Dis. & 2.94 & 3 & 3.28 & 1 & -1.45 & 15 & 2.43 & 2 \\
Tongzhou Dis. & -2.14 & 13 & 0.41 & 6 & -0.17 & 9 & -1.53 & 12 \\
Shunyi Dis. & 1.51 & 4 & 1.44 & 2 & 1.68 & 3 & 1.52 & 4 \\
Changping Dis. & -0.64 & 8 & -0.59 & 12 & 0.45 & 6 & -0.50 & 9 \\
Daxing Dis. & -2.71 & 15 & -0.31 & 11 & 0.14 & 7 & -2.00 & 15 \\
Development & 8.51 & 1 & -2.26 & 17 & 0.74 & 5 & 5.99 & 1 \\
Zone & & & & & & & \\
Mentougou Dis. & -2.83 & 16 & 0.35 & 7 & -0.40 & 11 & -2.07 & 16 \\
Huairou Dis. & 0.96 & 5 & 0.76 & 4 & 0.97 & 4 & 0.93 & 5 \\
Pinggu Dis. & -0.87 & 10 & 0.04 & 8 & 1.89 & 2 & -0.40 & 8 \\
Co Miyun & 0.28 & 7 & 1.20 & 3 & 2.11 & 1 & 0.64 & 6 \\
Co Yanqing & -2.84 & 17 & -0.29 & 10 & -0.53 & 13 & -2.18 & 17 \\
\hline
\end{tabular}


From Table 3, we can see that the first principal component $F_{1}$ reflects the Talent Effectiveness other than postgraduates and senior workers in the 17 areas. The top 3 areas are Beijing Economic and Technical Development Zone, Xicheng District and Fangshan District. The second principal component $F_{2}$ reflects the Talent Effectiveness of postgraduates. The top 4 areas are Fangshan District, Shunyi District, Miyun District and Huairen District. The third principal component for senior workers plays a relatively important role in areas of County Miyun, Pinggu District, Shunyi District and Huairen District. We get the overall ranking of F as we synthesize the three principal components, which is in accordance with $F_{1}$. The top 4 areas are the Development Zone, Xicheng District, Fangshan District and Shunyi District.

Based on the above research, we may come to the conclusion that where people can see a relatively intensive manufacturing industry, the Talent Effectiveness generally takes better effect. The Talent Effectiveness of secondary industry ranks top 4 in areas of the Development Zone, Xicheng District, Fangshan District and Shunyi District is a good case in example. This is especially true for Xicheng District, ranking No. 2 in Beijing Area, where talents play a better role as the proportion of Secondary increases after merging Xuanwu District. As for high-level talents like postgraduates or above and talents of high-tech, they can perform better in areas with intensive secondary industry companies, such as the Development Zone, Fangshan District, Shunyi District, and Huairou District, etc. In the central city areas (like Dongcheng District, Haidian District, and Chaoyang District, etc.), remote areas and counties (like County Yanqing, and Mentougou District, etc.), there are relatively few secondary industry companies, and the well-educated talents are making less contribution. The intensity of secondary industry companies influences the role of Talent Effectiveness, especially in high-tech industry, where talents have an obvious positive correlation with pushing forward the development of the industry and promoting the economic growth. Therefore, the decision-makers need to pay close attention to the allocation of human resources in secondary industry.

\subsection{Talent Effectiveness in Tertiary Industry}

Followed by the above principles, we can get the matrix index of Talent Effectiveness for tertiary industry (See Table III and IV in the Appendix for the original data).

Table 4. Matrix index of talent effectiveness for tertiary industry

\begin{tabular}{lcc}
\hline Eigenvectors & $\mathrm{F}_{1}$ & $\mathrm{~F}_{2}$ \\
\hline $\mathrm{X}_{01}{ }^{* *}$ & 0.0931 & 0.7540 \\
$\mathrm{X}_{02}{ }^{* *}$ & 0.2833 & -0.0838 \\
$\mathrm{X}_{03}{ }^{* *}$ & 0.2832 & -0.2427 \\
$\mathrm{X}_{04}{ }^{* *}$ & 0.2893 & -0.2162 \\
$\mathrm{X}_{05}{ }^{* *}$ & 0.2848 & -0.2674 \\
$\mathrm{X}_{06}{ }^{* *}$ & 0.2713 & 0.3413 \\
$\mathrm{X}_{07}{ }^{* *}$ & 0.3016 & -0.0058 \\
$\mathrm{X}_{08}{ }^{* *}$ & 0.2999 & -0.0769 \\
$\mathrm{X}_{09}{ }^{* *}$ & 0.2900 & 0.0305 \\
$\mathrm{X}_{10}{ }^{* *}$ & 0.2790 & 0.2737 \\
$\mathrm{X}_{11}{ }^{* *}$ & 0.2848 & 0.1824 \\
$\mathrm{X}_{12}{ }^{* *}$ & 0.2918 & -0.0299 \\
$\mathrm{X}_{13}{ }^{* *}$ & 0.2888 & -0.1222 \\
Eigenvalue & 10.6849 & 1.3949 \\
Contribution Rate of Variance & 0.8219 & 0.1073 \\
Accumulated Contribution Rate & 0.8219 & 0.9292 \\
\hline
\end{tabular}

According to the basic principle of KPCA, only the Eigenvalues of $\mathrm{F}_{1}$ and $\mathrm{F}_{2}$ are larger than 1, the rest less than 1 . Therefore, we only take the first two for further analysis. The first principal component holds small load to 
talents of postgraduates, and the same to other types of talents, which means that principal component $F_{1}$ reflects all the Talent Effectiveness information except for high-end talents like postgraduates. The second principal component holds large load to talents of postgraduates, and small to other types of talents, which means $\mathrm{F}_{2}$ mainly reflects the Talent Effectiveness information of high-end talents. We measure the first and second principal as well as synthetic value as follows:

Table 5. Comparison on talent effectiveness for tertiary industry

\begin{tabular}{lcccccc}
\hline Areas & $\mathrm{F}_{1}$ & Ranking $\mathrm{F}_{1}$ & $\mathrm{~F}_{2}$ & Ranking $\mathrm{F}_{2}$ & $\mathrm{~F}$ & Overall Ranking F \\
\hline Dongcheng Dis. & 0.1251 & 6 & -0.8922 & 15 & 0.0076 & 6 \\
Xicheng Dis. & 4.3347 & 2 & -1.4299 & 16 & 3.6689 & 2 \\
Chaoyang Dis. & 1.9609 & 4 & -0.5104 & 12 & 1.6755 & 4 \\
Fengtai Dis. & -1.4145 & 10 & -0.1546 & 10 & -1.2690 & 10 \\
Shijingshan Dis. & -1.0314 & 9 & -0.5848 & 13 & -0.9798 & 9 \\
Haidian Dis. & 0.9103 & 5 & -1.8495 & 17 & 0.5916 & 5 \\
Fangshan Dis. & -0.2875 & 7 & 0.9000 & 3 & -0.1503 & 7 \\
Tongzhou Dis. & -0.9607 & 8 & 0.5835 & 4 & -0.7823 & 8 \\
Shunyi Dis. & 2.7084 & 3 & 3.1610 & 1 & 2.7607 & 3 \\
Changping Dis. & -2.3525 & 15 & -0.8721 & 14 & -2.1815 & 16 \\
Daxing Dis. & -1.5220 & 11 & -0.0452 & 7 & -1.3515 & 11 \\
Development Zone & 9.8242 & 1 & 0.0863 & 6 & 8.6995 & 1 \\
Mentougou Dis. & -2.3714 & 16 & -0.0961 & 9 & -2.1086 & 15 \\
Huairou Dis. & -2.0519 & 13 & 0.4838 & 5 & -1.7590 & 13 \\
Pinggu Dis. & -2.3258 & 14 & -0.0610 & 8 & -2.0642 & 14 \\
Co Miyun & -2.0327 & 12 & 1.7478 & 2 & -1.5960 & 12 \\
Co Yanqing & -3.5129 & 17 & -0.4667 & 11 & -3.1611 & 17 \\
\hline
\end{tabular}

Table 5 illustrates that on the aspect of comprehensive utilization of talents in tertiary industry, the top 4 areas are those that have a relatively better economic development, such as the Development Zone, Xicheng District, Shunyi District and Chaoyang District. However, the high-end talents make better performance and have more influence in some suburbs, where the Talent Effectiveness is relatively low, such as Xicheng District, Haidian District, Dongcheng District and Chaoyang District. The above phenomena are in accordance with the effectiveness pattern of secondary industry. Next, we are going to make further comparison on the comprehensive Talent Effectiveness of secondary and tertiary industries with synthetic verification of the two industries.

\subsection{Comparisons on the Comprehensive Talent Effectiveness of Secondary and Tertiary Industries}

We put Talent Effectiveness of secondary and tertiary Industries together for verification (See Table V and VI in Appendix for original data) and find there are only two principal components whose eigenvalues are larger than 1. The statistical indicators are as follows. 
Table 6. Matrix index of talent effectiveness for secondary and tertiary industries in different areas of Beijing region

\begin{tabular}{lcc}
\hline Eigenvectors & $\mathrm{F}_{1}$ & $\mathrm{~F}_{2}$ \\
\hline $\mathrm{X}_{01}{ }^{* *}$ & 0.0630 & 0.7181 \\
$\mathrm{X}_{02}{ }^{* *}$ & 0.2906 & 0.1639 \\
$\mathrm{X}_{03}{ }^{* *}$ & 0.3072 & -0.0567 \\
$\mathrm{X}_{04}{ }^{* *}$ & 0.2630 & -0.2934 \\
$\mathrm{X}_{05}{ }^{* *}$ & 0.2934 & -0.2780 \\
$\mathrm{X}_{06}{ }^{* *}$ & 0.2627 & 0.3982 \\
$\mathrm{X}_{07}{ }^{* *}$ & 0.3038 & 0.0873 \\
$\mathrm{X}_{08}{ }^{* *}$ & 0.3090 & -0.0187 \\
$\mathrm{X}_{09}{ }^{* *}$ & 0.2935 & -0.0471 \\
$\mathrm{X}_{10}{ }^{* *}$ & 0.2950 & 0.0724 \\
$\mathrm{X}_{11}{ }^{* *}$ & 0.2374 & 0.2325 \\
$\mathrm{X}_{12}{ }^{* *}$ & 0.2945 & -0.1893 \\
$\mathrm{E}^{*}$ & 0.2982 & -0.1645 \\
Cigenvalue & 9.9671 & 1.6043 \\
Accumulated Contribution Rate & 0.7667 & 0.1234 \\
\hline
\end{tabular}

According to Table 6, only the eigenvalues of the first and second principal components are larger than 1 , and other principal values cannot meet the needs at all. Therefore, we choose principal components $F_{1}$ and $F_{2}$ to make further analysis on Talent Effectiveness for Secondary and Tertiary Industries in different areas. $F_{1}$ mainly reflects the Talent Effectiveness information for talents other than postgraduates, and the principal component to reflect postgraduates or above is $F_{2}$. The rankings of $F_{1}, F_{2}$ and synthetic component $F$ are shown in Table 7 as follows.

Table 7. Comprehensive comparison on talent effectiveness for secondary and tertiary industries in different areas of Beijing region

\begin{tabular}{lcccccc}
\hline & $\mathrm{F}_{1}$ & Ranking $\mathrm{F}_{1}$ & $\mathrm{~F}_{2}$ & Ranking $\mathrm{F}_{2}$ & $\mathrm{~F}$ & Overall Ranking F \\
\hline Dongcheng Dis. & -0.1263 & 7 & -1.2116 & 15 & -0.2767 & 8 \\
Xicheng Dis. & 4.7638 & 2 & -1.9330 & 16 & 3.8356 & 2 \\
Chaoyang Dis. & 1.1479 & 4 & -0.8823 & 14 & 0.8665 & 4 \\
Fengtai Dis. & -1.9735 & 14 & -0.4018 & 11 & -1.7557 & 14 \\
Shijingshan Dis. & -0.3577 & 8 & -0.2784 & 10 & -0.3467 & 9 \\
Haidian Dis. & 0.5836 & 6 & -2.1371 & 17 & 0.2065 & 6 \\
Fangshan Dis. & 0.7321 & 5 & 1.5623 & 2 & 0.8472 & 5 \\
Tongzhou Dis. & -1.7058 & 12 & 0.6547 & 5 & -1.3787 & 11 \\
Shunyi Dis. & 2.1205 & 3 & 2.6951 & 1 & 2.2002 & 3 \\
Changping Dis. & -1.6313 & 10 & -0.5931 & 12 & -1.4874 & 12 \\
Daxing Dis. & -2.2334 & 15 & -0.0798 & 8 & -1.9349 & 15 \\
Development Zone & 9.2226 & 1 & 0.4244 & 6 & 8.0032 & 1 \\
Mentougou Dis. & -3.0279 & 16 & -0.2231 & 9 & -2.6392 & 16 \\
Huairou Dis. & -0.5020 & 9 & 1.1536 & 4 & -0.2725 & 7 \\
Pinggu Dis. & -1.8799 & 13 & 0.1845 & 7 & -1.5938 & 13 \\
Co Miyun & -1.6559 & 11 & 1.5362 & 3 & -1.2135 & 10 \\
Co Yanqing & -3.8284 & 17 & -0.6620 & 13 & -3.3896 & 17 \\
\hline
\end{tabular}


As we make comprehensive comparison on Talent Effectiveness for secondary and tertiary Industries among 17 areas, the rankings the two principal components and the comprehensive ranking are consistent with those made on separate industry, i. e., the ranking Talent Effectiveness in areas with higher economic levels are also in the lead. However, as for the role of high-end talents, the Talent Effectiveness in the suburb is higher. We hold the idea that the intensity of high-level talents is big in such central areas as Haidian District, Xicheng District, Dongcheng District and Chaoyang District, whereas the intensity of high-level talents is small in the suburb. As for high-end talents on average unit, the unit contribution of high-level talents in central areas is not as big as those in the suburb, for the space for career development is more restricted, which is verified by the facts. In order to understand the differences more directly on the overall Talent Effectiveness and Talent Effectiveness of high-level talents, we categorize them according to certain criteria, and the results are shown in Table 8.

Table 8. Comparison results on overall talent effectiveness and high-level talent effectiveness in Beijing region

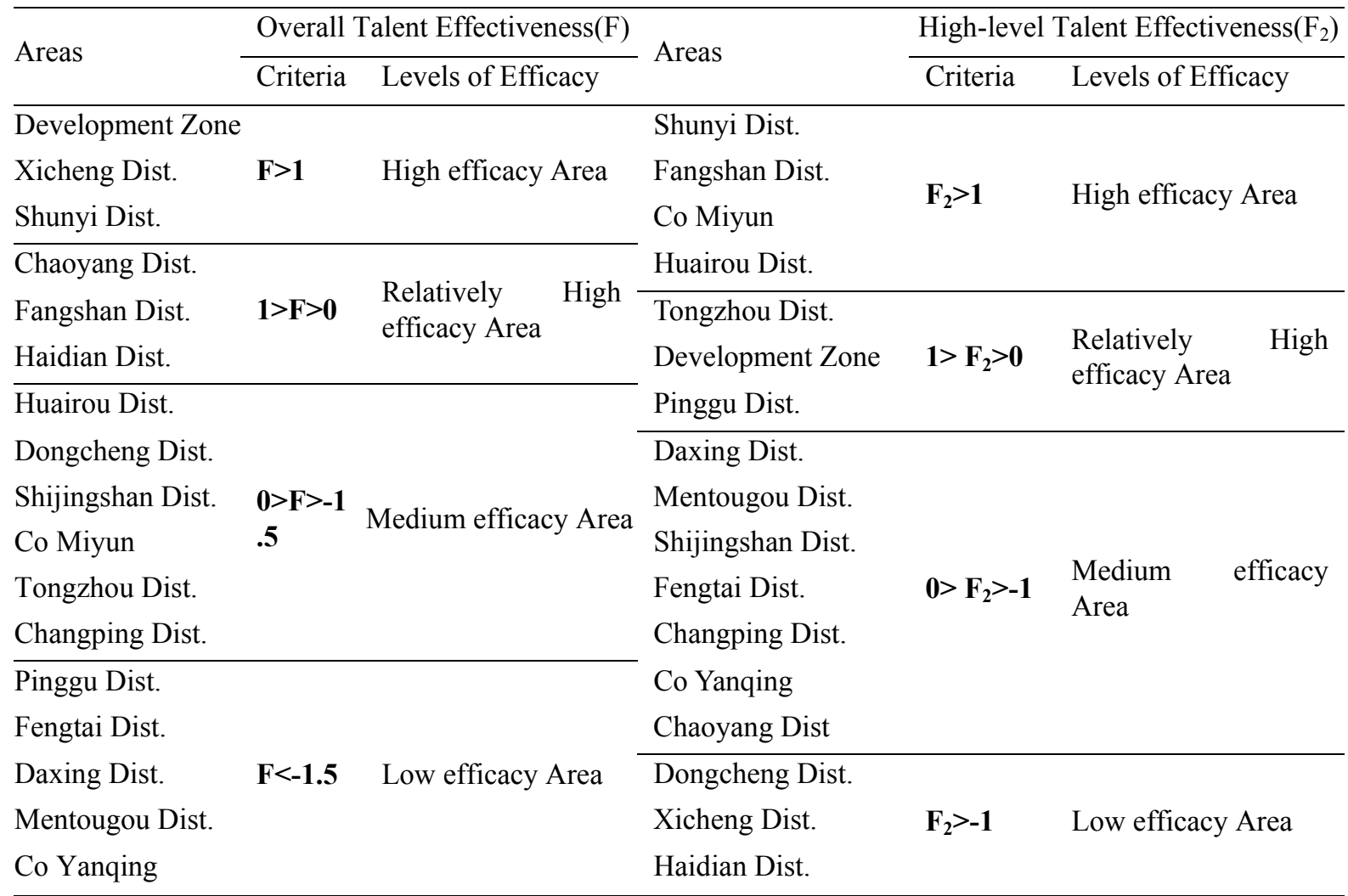

Table 8 illustrates that the overall Talent Effectiveness of central areas in Beijing Region is higher than that of suburbs and counties, while the high-level Talent Effectiveness is quite opposite, with efficacy of suburbs and counties higher than that of central areas. The above phenomenon is consistent with the previous conclusion.

\section{Conclusions and Discussions}

We have taken the second Economic Census Data of Beijing Area to make research on the Talent Effectiveness data in 17 areas of Beijing Region, and compare Talent Effectiveness and ranking in 17 areas with Principal Component Analysis. The results showed that: 1. The overall Talent Effectiveness is in positive correlation with the economic development level, i.e., the overall Talent Effectiveness is relatively high in central areas with high economic development. 2. Talents with postgraduates or above have higher Talent Effectiveness in suburbs and counties than that in central areas. Based on the above conclusions, we made the discussion as follows:

First, the economic development level in central areas is generally higher than that of suburbs, and the overall allocation of talent resources is better than suburbs and counties, especially in the central areas with high-intensity of talents in Secondary and tertiary industries. According to the second Economic Census Data, the proportion of talents in Secondary and Tertiary Industries in the 6 central areas accounts for $58.7 \%$ of secondary industry and $85.54 \%$ of tertiary industry, and that of suburbs and counties $41.3 \%$ and $14.46 \%$. The enterprise income amounts for $79.75 \%$ and $20.25 \%$ respectively in central areas, which shows that the overall 
Talent Effectiveness and effectiveness in central areas are higher than those of suburbs and counties. Why can central areas attract so many talents? The probable reason may be in relation with the distribution of headquarters of companies. At present, there are 784 level one headquarters, among which 665 are located in the 6 central areas, accounting for $84.82 \%$, and only 119 are located in suburbs and counties. The top 3 areas with the largest number of level one headquarters are Haidian District, Chaoyang District and Xicheng District, with the percentages of level one headquarters of $25.1 \%, 23.5 \%$ and $16.3 \%$ respectively, which total $64.9 \%$. The distribution pattern of headquarters is consistent with the talent locational structural distribution, for the capacity for employees of headquarters is higher than other social organizations.

Second, the proportion of middle and high-level talents in central areas is higher than that in suburbs and counties. According to the Census Data, the proportions of talents with middle and high-level technical titles in secondary and tertiary industries in central areas are $64 \%$ and $85.75 \%$ respectively, while only $36 \%$ and $14.25 \%$ in suburbs and counties. From the perspective of higher education, the proportion of talents with master's degree or above accounts for $90.77 \%$ in central areas, while less than $10 \%, 9.23 \%$ to be specific. The distribution structure of high-end talents seriously deviates from the correspondent enterprise income proportion. It can be understood that the highly-educated talents are "excessively-concentrated" in central areas, while "insufficient" in suburbs and counties. The coexistence of the two phenomena, not only directly causes the overall Talent Effectiveness not to be high in Beijing Region (Note 7), but also lowers the Talent Effectiveness of the "excessively-concentrated" central areas. Therefore, it's not difficult to understand that the Talent Effectiveness of the highly-educated talents in central areas is lower than that in suburbs.

Third, from the perspective of social practice, we can understand like this: in the central areas with intensive high-level talents, the enterprises have many choices for talents, but it does not necessarily mean they can assign the talents well, especially lack of attention of assigning key talents to critical positions. Therefore, the entrepreneurs may neglect to stimulate the motives of the talents in facing the situation of talents oversupply. However, the entrepreneurs in the suburb pay close attention to the highly-educated talents suitable for their enterprises, try to assign them to the suitable positions, and try to make full use of their potentials. To the talents, if the enterprises pay attention to them, they may get more opportunities for further development, and their enthusiasm for work could be improved, which may lead to an improvement of Talent Effectiveness.

Based on the above three points, we suggest promoting balanced development of talents in central areas and suburbs with the mode of integrating the urban and rural talents. The concrete ideas are as follows: First, transfer the unsuitable industries or industries inappropriate in central areas to suburbs, to realize the talents flow with industry transfer. Second, with the pair work of urban and rural areas, provide talents help to suburb from central areas, which can be flexible flow or rigid support. Last, improve the income level of talents in suburbs with increasing investment of talent capital in suburb.

\section{References}

Cai, T., \& Liu, J. S. (2012). The relationship between regional industrial similarity and shortage of labors. Technical economy, 2012(5), 60-65.

Chen A. M. (2007). Comprehensive evaluation of regional talent efficiency based on talent structure. Journal of Chongqing university.(natural science edition), 2007(8), 149-159.

Edward F. D. (1985). Trends in American Economic Growth: 1929-1982 (pp. 37-60). The Brookings Institution, Washington D.C.

Gui, Z. M. (2009). Theoretical research on contribution rate of human capital to economic growth. Chinese talent, 2009(12), 10-13.

Jiang, L., \& Ji, M. H. (2011). The impact on emergency efficiency of technology advancement---from the view of special heterogeneity. Technical economy, 2011(11), 73-78.

Li, H. Z., et al. (2010). Measurement and indicator building of Chinese human capital. Economic research, 2010(8), 42-54.

Li, Q., \& Chen, P. (2006). Analysis and solutions on talent efficiency in China. Theory and practice of system engineering, 2006(5), 72-77.

Lucas, R. E. (1988). On the Mechanics of Economic Development. Journal of Monetary Economics, 1988(22), 3-42. http://dx.doi.org/10.1016/0304-3932(88)90168-7

Ma, N., Wang, X. H., et al. (2011). Contribution rate of talent in economic growth in Beijing. Human resource exploitation in China, 2011(4), 5-12. 
O'neill Donel. (1995). Education and Income Growth: Implications for Cross-Counties Inequality. Journal of Political Economic, 103(6). http://dx.doi.org/10.1086/601455

Pan, C. G., \& Wang, L. (2004). The report on development of Chinese talent (p. 252). Social science literature press.

Robert, J. B. (1991). Economic growth in a cross section of countries. The Quarterly Journal of Economics, 106(2), 407-443. http://dx.doi.org/10.2307/2937943

Schultz, T. W. (1960). Capital Formation by Education. Journal of Political Economy, 1960(68), 571-583. http://dx.doi.org/10.1086/258393

Schultz, T. W. (1961). Investment in Human Capital. American Economic Review, 1961(3), 1-17.

Wang, M. M., \& Wang, X. H. (2010). Research on regional human resource allocation efficiency in China--based on empirical analysis of inter-provincial panel data. New view, 2010(6), 18-20.

Wang, X. H., Cao, L. F., et al. (2011). Comparative research on talent efficency in Bejing. Human resource exploitation in China, 2011(5), 9-15.

Wang, Z. Q., \& Wang, H. C. (2004). Research on measurement hierarchy system of human resources efficiency. Business economy, 2004(12), 27-28.

Wang, X. L., et al. (2009). China's economic transformation mode and the sustainability of growth. Economy research, 1, 4-16.

Yang, B. (2004). Japanese operation based on maximizing the effectiveness of internal human resources. Nankai bussiness review, 2004(3), 57-62.

Yang, Z. J., \& Lu, M. F. (2011). Empirical research on relationship between the transfer of rural labor and the income gap. Journal of Jishou University (social science edition), 32(4), 95-97.

Zhou, X., \& Wang, X. H. (2012). International talent in Beijing: gap and route-based on the comparative view between New York, London and Tokyo. Human resource exploitation in China, 2012(4), 65-70.

\section{Notes}

Note 1. Stated in Outline of National Medium- and Long-term Development Planning (2010-2020) as follows, "Talents are the labors with relatively high capacities and qualities in human resources". We extend the meaning as follows, "Talent capital is the advanced section of human capital."

Note 2. Data are from China Labor Statistical Yearbook 2011, China Statistics Press, May 2012.

Note 3. Data about academicians of the Chinese Academy of Sciences and Chinese Academy of Engineering, "Thousand Talents Program" and "Overseas Talents Aggregation Program" are from Beijing Leading Group Office of Talent Affairs.

Note 4. In government planning, some areas take the Talent Effectiveness indexes to set the goal of development, for example, Shenzhen has planned to lower the Talent Effectiveness index to 2.16 in 2010 from 3.13 in 2004 in its Eleventh "Five-Year" Plan.

Note 5. There are 16 administrative districts and counties in Beijing Region now, in which the data of original Chongwen District and Dongcheng District have been merged into Dongcheng District, while Xuanwu District and Xicheng District into Xicheng District. We have taken Beijing Economic and Technical Development Zone as an individual area. Therefore, there are a total of 17 areas.

Note 6. In the cross section comparison, we think the method is feasible because non-talent factors have been taken out of the objects of comparison, i.e., the identity of criteria does not affect the results of comparison, especially when the results are used for ranking. Besides, if we adopt this method to measure talent effectiveness and make comparison in the same region, the credibility of the results is higher, because the variability of allocating the production factors within a certain range is relatively low, while the differences of technical levels is not very big, thus increasing the reliability of the method.

Note 7. In the research of Wang Xuanhua(2010, 2011b) on the talent effectiveness across China, he has found that Beijing Region ranks 26 on overall talent effectiveness in the 30 regions (excluding Tibet) of China mainland. 


\section{Appendix}

Appendix 1. Structural distribution of employees in secondary industry in Beijing (Unit: 100 million CNY/ 10 thousand persons)

\begin{tabular}{|c|c|c|c|c|c|c|c|c|c|c|c|c|c|c|}
\hline Areas & $\mathrm{y}$ & $\mathrm{x}_{1}$ & $\mathrm{x}_{2}$ & $\mathrm{x}_{3}$ & $\mathrm{x}_{4}$ & $\mathrm{X}_{5}$ & $\mathrm{x}_{6}$ & $\mathrm{x}_{7}$ & $\mathrm{X}_{8}$ & $\mathrm{X}_{9}$ & $\mathrm{x}_{10}$ & $\mathrm{x}_{11}$ & $\mathrm{x}_{12}$ & $\mathrm{x}_{13}$ \\
\hline cheng Dis. & 354.65 & 0.08 & 0.87 & 0.98 & 1.63 & & & & 0.75 & 0.02 & 0.06 & 0.26 & 0.30 & 0.21 \\
\hline & & 0.16 & & & & & & & & & & & .53 & 0.40 \\
\hline Chaoyang Dis. & & 0.44 & 3.72 & 4.92 & 7.61 & & & & & & & 1.63 & 1.33 & 1.37 \\
\hline Dis. & 1081.20 & 0.33 & 2.33 & 2.78 & 5.20 & 6.07 & 0.66 & 1.58 & 2.08 & 0.08 & 0.29 & 1.16 & 1.35 & 1.80 \\
\hline Shijingshan Dis. & 963.24 & 0.14 & 1.15 & 1.45 & 2.96 & 2.20 & 0.22 & & 0.99 & & 0.20 & 1.33 & 1.27 & 0.86 \\
\hline Haic & 2526.04 & 1.37 & 6.76 & 5.99 & 6.60 & 7.32 & 1.30 & 3.04 & 3.69 & 0.32 & 0.47 & 1.16 & 1.29 & 1.59 \\
\hline Fangshan Dis. & 1051.36 & 0.07 & 0.90 & 1.26 & 2.20 & 4.87 & 0.13 & 0.47 & 0.81 & 0.06 & 0.17 & 0.76 & 0.89 & 0.68 \\
\hline & & & & & & & & & & & & & & 2.50 \\
\hline Shunyi Dis. & 1384.00 & 0.16 & 1.68 & 2.25 & 6.72 & 8.38 & 0.19 & 0.75 & 1.35 & 0.10 & 0.17 & 0.31 & 0.95 & 1.27 \\
\hline & & & & & & & & & & & & & 0.75 & 1.05 \\
\hline g Dis. & 524.09 & 0.12 & 1.27 & 2.16 & 5.39 & 6.28 & 0.25 & 0.80 & 1.14 & 0.08 & 0.20 & 0.35 & 0.68 & 1.18 \\
\hline nt Zone & 2141 & 0.40 & & & & & & & & & & & 0.54 & 0.33 \\
\hline Mentougou Dis. & 110.24 & 0.02 & 0.26 & 0.46 & 1.16 & 2.46 & 0.05 & & 0.30 & 0.01 & 0.04 & 0.22 & 0.25 & 1.26 \\
\hline Huairou Dis. & 402.82 & 0.05 & 0.58 & 0.78 & 2.47 & 2.51 & 0.07 & & & 0.01 & 0.04 & 0.19 & 0.23 & 0.45 \\
\hline Pinggu Dis. & 212.63 & 0.05 & 0.37 & 0.64 & 1.92 & 2.44 & 0.05 & & & 0.01 & 0.03 & 0.05 & 0.20 & 0.38 \\
\hline Co Miyun & 193.53 & 0.02 & 0.31 & 0.52 & 1.89 & 3.54 & 0.06 & 0.15 & 0.32 & 0.01 & 0.01 & 0.07 & 0.10 & 0.35 \\
\hline Co Yanqing & 65.31 & 0.02 & 0.12 & 0.24 & 0.52 & 0.88 & 0.04 & 0.12 & 0.16 & 0.01 & 0.03 & 0.08 & 0.10 & 0.15 \\
\hline
\end{tabular}

Note: Meanings of codes in Table I: $\mathrm{y}$-total enterprise income in secondary industry; $\mathrm{x}_{1}$ - $\mathrm{x}_{13}$ hierarchical structure of employees, $\mathrm{x}_{1}$-postgraduates or above, $\mathrm{x}_{2}$-bachelor's degree, $\mathrm{x}_{3}$-college diploma, $\mathrm{x}_{4}$-senior middle schooling, $\mathrm{x}_{5}$-junior middle schooling or below; $\mathrm{x}_{6}$-senior technical title, $\mathrm{X}_{7}$-medium technical title, $\mathrm{X}_{8}$-junior technical title; $\mathrm{X}_{9}$-senior technician, $\mathrm{X}_{10}$-technician, $\mathrm{X}_{11}$-senior worker, $\mathrm{X}_{12}$-medium worker, $\mathrm{X}_{13}$-junior worker.

Appendix 2. Evaluation matrix for talent effectiveness of secondary industry in Beijing (Million CNY/Person)

\begin{tabular}{|c|c|c|c|c|c|c|c|c|c|c|c|c|c|}
\hline Areas & $\mathrm{x}_{1}^{*}$ & $\mathrm{x}_{2} *$ & $\mathrm{x}_{3} *$ & $\mathrm{x}_{4}^{*}$ & $\mathrm{x}_{5}^{*}$ & $\mathrm{x}_{6}^{*}$ & $\mathrm{x}_{7} *$ & $\mathrm{x}_{8} *$ & $\mathrm{X}_{9} *$ & $\mathrm{x}_{10} *$ & $\mathrm{x}_{11}$ * & $\mathrm{x}_{12} *$ & $\mathrm{x}_{13} *$ \\
\hline Dongcheng Dis. & 43.09 & 4.07 & 3.62 & 2.18 & 2.71 & 20.63 & 7.10 & 4.70 & 164.95 & 62.33 & 13.47 & 11.70 & 17.12 \\
\hline & 70.47 & & 8.60 & 6.49 & 7.00 & 41.66 & & & & & & & 27.70 \\
\hline Chao & 30.70 & 3.62 & 2.73 & 1.77 & 1.96 & 19.80 & 6.88 & 4.53 & & & & 10.10 & 9.86 \\
\hline Feng & 2.70 & 4.65 & 3.89 & 2.08 & & & & 5.20 & & & & 8.00 & 6.01 \\
\hline & 71.04 & 8.35 & 6.64 & & 4.38 & & & & & & & 7.56 & 1126 \\
\hline Haidi & & 3.74 & 4.22 & 3.83 & 3.45 & 19.50 & & 6.85 & & & & & 15.93 \\
\hline & 150.63 & 11.69 & 8.31 & & 2.16 & & & & & & & & 15.50 \\
\hline Tongzhou Dis. & 59.00 & & 3.38 & 1.24 & 0.85 & 26.92 & & 4.90 & & & & 5.04 & 2.87 \\
\hline Shur & 88.38 & & 6.14 & 2.06 & 1.65 & & & & & & & & 10.88 \\
\hline Changpi & & & & & & & & & & & & & 8.66 \\
\hline Daxil & & & 2.43 & 0.97 & 0.83 & 20.63 & & 4.60 & & & & 7.66 & 4.45 \\
\hline & & & & & & & & & & & & & \\
\hline Mentougou Dis. & 64.85 & 4.22 & 2.42 & 0.95 & 0.45 & 22.68 & 7.07 & 3.65 & 112.49 & & 4.90 & 4.44 & 0.88 \\
\hline Huairou Dis. & & 6.97 & & 1.63 & & 55.11 & & 7.37 & & & 20.70 & 17.63 & 9.05 \\
\hline Pinggu Dis. & & & & 1.11 & 0.87 & 39.45 & & 5.93 & & & & & 5.67 \\
\hline Co Miyun & 115.89 & 6.27 & 3.73 & 1.03 & 0.55 & 33.83 & & 6.11 & 210.36 & 143.36 & 27.97 & 18.92 & 5.61 \\
\hline Co Yanqing & 35.89 & 5.35 & 2.74 & 1.26 & 0.74 & 16.33 & 5.61 & 4.09 & 55.82 & 22.68 & 7.73 & 6.42 & 4.42 \\
\hline
\end{tabular}

Note: In Table II, $\mathrm{x}_{1}{ }^{*}-\mathrm{x}_{13}{ }^{*}$ indicate Talent Effectiveness Index in secondary industry (positive index) 
Appendix 3. Structural distribution of employees in tertiary industry in Beijing (Unit: 100 million CNY/ 10 thousand persons)

\begin{tabular}{lcccccccccccccc}
\hline Areas & $\mathrm{y}$ & $\mathrm{x}_{1}$ & $\mathrm{x}_{2}$ & $\mathrm{x}_{3}$ & $\mathrm{x}_{4}$ & $\mathrm{x}_{5}$ & $\mathrm{x}_{6}$ & $\mathrm{x}_{7}$ & $\mathrm{x}_{8}$ & $\mathrm{x}_{9}$ & $\mathrm{x}_{10}$ & $\mathrm{x}_{11}$ & $\mathrm{x}_{12}$ & $\mathrm{x}_{13}$ \\
\hline Dongcheng Dis. & 4237 & 3.99 & 17.33 & 14.19 & 16.63 & 8.53 & 2.76 & 5.30 & 5.68 & 0.19 & 0.43 & 1.85 & 2.55 & 2.25 \\
Xicheng Dis. & 9450 & 5.95 & 19.48 & 15.20 & 14.92 & 8.82 & 4.21 & 7.15 & 7.83 & 0.24 & 0.53 & 1.82 & 1.89 & 2.56 \\
Chaoyang Dis. & 11295 & 8.59 & 37.36 & 29.05 & 35.28 & 21.37 & 5.06 & 9.43 & 9.54 & 0.37 & 0.75 & 2.05 & 3.53 & 4.47 \\
Fengtai Dis. & 2299 & 1.65 & 8.78 & 10.13 & 22.35 & 19.64 & 1.75 & 3.99 & 5.22 & 0.15 & 0.34 & 2.97 & 4.94 & 3.74 \\
Shijingshan Dis. & 546 & 0.49 & 2.55 & 2.33 & 3.81 & 2.48 & 0.52 & 1.08 & 1.05 & 0.03 & 0.08 & 0.33 & 0.35 & 0.44 \\
Haidian Dis. & 13469 & 16.30 & 49.06 & 33.08 & 37.17 & 21.18 & 10.60 & 17.45 & 14.81 & 0.68 & 1.69 & 9.68 & 3.76 & 3.40 \\
Fangshan Dis. & 507 & 0.22 & 2.20 & 2.01 & 2.70 & 2.89 & 0.32 & 1.15 & 1.20 & 0.02 & 0.04 & 0.16 & 0.24 & 0.36 \\
Tongzhou Dis. & 510 & 0.26 & 2.36 & 2.52 & 3.28 & 3.28 & 0.32 & 1.08 & 1.29 & 0.03 & 0.06 & 0.17 & 0.30 & 0.50 \\
Shunyi Dis. & 1439 & 0.41 & 4.43 & 5.41 & 6.18 & 4.89 & 0.34 & 1.18 & 1.42 & 0.05 & 0.05 & 0.18 & 0.43 & 0.65 \\
Changping Dis. & 486 & 0.83 & 3.53 & 3.57 & 4.73 & 4.56 & 0.70 & 1.50 & 1.70 & 0.05 & 0.08 & 0.32 & 0.52 & 0.76 \\
Daxing Dis. & 530 & 0.39 & 2.94 & 2.91 & 4.55 & 4.11 & 0.44 & 1.20 & 1.45 & 0.04 & 0.07 & 0.22 & 0.45 & 0.53 \\
Development & 878 & 0.41 & 1.77 & 1.34 & 1.22 & 0.67 & 0.19 & 0.32 & 0.42 & 0.02 & 0.02 & 0.05 & 0.07 & 0.09 \\
Zone & & & & & & & & & & & & \\
Mentougou Dis. & 89 & 0.08 & 0.90 & 1.04 & 1.29 & 0.96 & 0.10 & 0.42 & 0.47 & 0.01 & 0.01 & 0.08 & 0.08 & 0.10 \\
Huairou Dis. & 112 & 0.07 & 1.14 & 0.98 & 1.54 & 1.17 & 0.14 & 0.57 & 0.57 & 0.01 & 0.01 & 0.09 & 0.10 & 0.15 \\
Pinggu Dis. & 127 & 0.09 & 1.22 & 0.95 & 1.39 & 1.10 & 0.19 & 0.58 & 0.56 & 0.01 & 0.02 & 0.08 & 0.14 & 0.13 \\
Co Miyun & 155 & 0.05 & 1.25 & 1.28 & 1.70 & 1.65 & 0.13 & 0.58 & 0.68 & 0.01 & 0.03 & 0.10 & 0.16 & 0.20 \\
Co Yanqing & 46 & 0.05 & 1.01 & 0.85 & 1.05 & 1.18 & 0.11 & 0.49 & 0.55 & 0.02 & 0.02 & 0.11 & 0.14 & 0.14 \\
\hline
\end{tabular}

Note: Meanings of codes in Table III: $\mathrm{y}$-total enterprise income in Tertiary Industry; $\mathrm{x}_{1}-\mathrm{x}_{13}$ hierarchical structure of employees, $\mathrm{x}_{1}$-postgraduates or above, $\mathrm{x}_{2}$-bachelor's degree, $\mathrm{x}_{3}$-college diploma, $\mathrm{x}_{4}$-senior middle schooling, $\mathrm{x}_{5}$-junior middle schooling or below; $\mathrm{x}_{6}$-senior technical title, $\mathrm{X}_{7}$-medium technical title, $\mathrm{X}_{8}$-junior technical title; $\mathrm{X}_{9}$-senior technician, $\mathrm{X}_{10}$-technician, $\mathrm{X}_{11}$-senior worker, $\mathrm{X}_{12}$-medium worker, $\mathrm{X}_{13}$-junior worker.

Appendix 4. Evaluation matrix for talent effectiveness of tertiary industry in Beijing (Unit: Million CNY/Person)

\begin{tabular}{lccccccccccccc}
\hline Areas & $\mathrm{x}_{1}{ }^{*}$ & $\mathrm{x}_{2}{ }^{*}$ & $\mathrm{x}_{3}{ }^{*}$ & $\mathrm{x}_{4}{ }^{*}$ & $\mathrm{x}_{5}{ }^{*}$ & $\mathrm{x}_{6}{ }^{*}$ & $\mathrm{x}_{7}{ }^{*}$ & $\mathrm{x}_{8}{ }^{*}$ & $\mathrm{x}_{9}{ }^{*}$ & $\mathrm{x}_{10}{ }^{*}$ & $\mathrm{x}_{11}{ }^{*}$ & $\mathrm{x}_{12}{ }^{*}$ & $\mathrm{x}_{13}{ }^{*}$ \\
\hline Dongcheng Dis. & 10.61 & 2.44 & 2.99 & 2.55 & 4.96 & 15.35 & 8.00 & 7.46 & 220.47 & 99.31 & 22.96 & 16.62 & 18.80 \\
Xicheng Dis. & 15.87 & 4.85 & 6.22 & 6.33 & 10.72 & 22.45 & 13.22 & 12.06 & 390.03 & 179.53 & 52.03 & 49.89 & 36.88 \\
Chaoyang Dis. & 13.14 & 3.02 & 3.89 & 3.20 & 5.29 & 22.32 & 11.98 & 11.84 & 302.33 & 151.39 & 55.06 & 32.04 & 25.28 \\
Fengtai Dis. & 13.92 & 2.62 & 2.27 & 1.03 & 1.17 & 13.12 & 5.76 & 4.40 & 151.24 & 67.55 & 7.75 & 4.66 & 6.15 \\
Shijingshan Dis. & 11.20 & 2.14 & 2.35 & 1.43 & 2.21 & 10.55 & 5.07 & 5.22 & 218.47 & 69.58 & 16.50 & 15.44 & 12.32 \\
Haidian Dis. & 8.26 & 2.75 & 4.07 & 3.62 & 6.36 & 12.71 & 7.72 & 9.09 & 197.00 & 79.66 & 13.91 & 35.81 & 39.57 \\
Fangshan Dis. & 23.41 & 2.30 & 2.52 & 1.87 & 1.76 & 15.71 & 4.42 & 4.23 & 280.14 & 114.72 & 32.34 & 21.20 & 14.21 \\
Tongzhou Dis. & 19.74 & 2.16 & 2.02 & 1.56 & 1.56 & 15.97 & 4.71 & 3.95 & 174.68 & 80.96 & 30.56 & 17.05 & 10.26 \\
Shunyi Dis. & 34.74 & 3.25 & 2.66 & 2.33 & 2.94 & 42.88 & 12.21 & 10.14 & 294.25 & 301.02 & 78.97 & 33.85 & 22.09 \\
Changping Dis. & 5.89 & 1.38 & 1.36 & 1.03 & 1.07 & 6.99 & 3.25 & 2.86 & 94.56 & 59.20 & 15.41 & 9.31 & 6.36 \\
Daxing Dis. & 13.47 & 1.80 & 1.82 & 1.17 & 1.29 & 12.02 & 4.43 & 3.64 & 142.14 & 80.82 & 24.36 & 11.89 & 10.08 \\
Development Zone & 21.28 & 4.96 & 6.54 & 7.20 & 13.11 & 45.14 & 27.28 & 20.91 & 522.63 & 395.51 & 172.84 & 133.84 & 92.52 \\
Mentougou Dis. & 11.57 & 0.99 & 0.86 & 0.69 & 0.93 & 8.74 & 2.11 & 1.90 & 153.62 & 73.64 & 11.51 & 11.01 & 8.96 \\
Huairou Dis. & 16.81 & 0.98 & 1.15 & 0.73 & 0.96 & 8.14 & 1.97 & 1.95 & 199.62 & 114.07 & 12.98 & 11.41 & 7.57 \\
Pinggu Dis. & 13.62 & 1.04 & 1.34 & 0.92 & 1.15 & 6.86 & 2.20 & 2.26 & 97.83 & 75.70 & 16.60 & 9.16 & 9.75 \\
Co Miyun & 31.48 & 1.24 & 1.21 & 0.91 & 0.94 & 11.64 & 2.66 & 2.29 & 116.68 & 51.56 & 15.01 & 9.55 & 7.92 \\
Co Yanqing & 9.16 & 0.46 & 0.54 & 0.44 & 0.39 & 4.19 & 0.94 & 0.84 & 30.37 & 23.58 & 4.31 & 3.25 & 3.41 \\
\hline
\end{tabular}

Note: In Table IV, $\mathrm{x}_{1}{ }^{*}-\mathrm{x}_{13}{ }^{*}$ indicate Talent Effectiveness Index in Tertiary Industry (positive index). 
Appendix 5. Structural distribution of employees in secondary and tertiary industries in Beijing (Unit: 100 million CNY/ 10 thousand persons)

\begin{tabular}{|c|c|c|c|c|c|c|c|c|c|c|c|c|c|c|}
\hline Areas & $\mathrm{y}$ & $\mathrm{x}_{1}$ & $\mathrm{x}_{2}$ & $\mathrm{x}_{3}$ & $\mathrm{x}_{4}$ & $\mathrm{x}_{5}$ & $\mathrm{x}_{6}$ & $\mathrm{x}_{7}$ & $\mathrm{x}_{8}$ & $\mathrm{X}_{9}$ & $\mathrm{x}_{10}$ & $\mathrm{x}_{11}$ & $\mathrm{x}_{12}$ & $\mathrm{x}_{13}$ \\
\hline Dongcheng Dis. & 829.43 & 1981.67 & 8.07 & 35.54 & 29.35 & 34.88 & 18.38 & 5.69 & 11.09 & 12.12 & 0.41 & 0.91 & 3.95 & 5.40 \\
\hline Xicheng Dis. & 20007.77 & & 12.07 & & & & & & 14.90 & & & & 4.58 & 4.32 \\
\hline Chaoyang Dis. & 23936.80 & 2425.59 & 17.63 & 78.43 & 63.02 & 78.17 & 49.60 & 10.80 & 20.81 & 22.06 & 0.93 & 1.95 & 5.73 & 8.38 \\
\hline Fengtai Dis. & 5678.75 & 348.11 & 3.63 & 19.88 & 23.04 & 49.90 & 45.35 & 4.16 & 9.56 & 12.52 & 0.39 & 0.97 & 7.10 & 11.23 \\
\hline Shijingshan Dis. & 055.61 & 41.99 & 1.11 & 6.26 & 6.10 & 10.58 & 7.15 & 1.25 & 2.75 & 3.09 & 0.09 & 0.35 & 1.99 & 1.98 \\
\hline Haidian Dis. & 29463.90 & 1002.58 & 33.98 & 104.87 & 72.15 & 80.94 & 49.67 & 22.50 & 37.94 & 33.32 & 1.68 & 3.85 & 20.53 & 8.82 \\
\hline Fangshan Dis. & 2065.47 & -30.45 & 0.50 & 5.31 & 5.29 & 7.61 & 10.65 & 0.77 & 2.76 & 3.21 & 0.10 & 0.26 & 1.07 & 1.37 \\
\hline Tongzhou Dis. & 1737.03 & 46.34 & 0.64 & 6.00 & 7.16 & 12.33 & 15.00 & 0.91 & 3.06 & 4.05 & 0.13 & 0.33 & 0.90 & 2.02 \\
\hline & & & 0.99 & 10.53 & 13.08 & 19.09 & 18.16 & 0.86 & 3.11 & 4.19 & 0.20 & 0.27 & 0.67 & 1.80 \\
\hline Changping Dis. & 1882.60 & 74.32 & 1.91 & 8.85 & 9.09 & 13.13 & 13.78 & 1.69 & 3.78 & 4.52 & 0.17 & 0.31 & 0.97 & 1.80 \\
\hline & & & 0.90 & & 7.98 & & 14.49 & 1.14 & 3.20 & 4.05 & 0.16 & & 0.79 & 1.58 \\
\hline Development Zone & 3897.14 & 437.98 & 1.22 & 5.71 & 4.81 & 8.10 & 2.95 & 0.62 & 1.26 & 1.65 & 0.08 & 0.18 & 0.69 & 0.67 \\
\hline Mentougou Dis. & 288.44 & & 0.17 & 2.05 & 2.53 & 3.73 & 4.38 & 0.25 & 1.00 & 1.24 & 0.02 & 0.07 & 0.38 & 0.41 \\
\hline Huairou Dis. & 626.39 & 14.90 & 0.18 & 2.86 & 2.73 & 5.55 & 4.85 & 0.35 & 1.40 & 1.69 & 0.03 & 0.06 & 0.37 & 0.42 \\
\hline Pinggu Dis. & 467.00 & 21.82 & 0.23 & 2.80 & 2.54 & 4.70 & 4.65 & 0.42 & 1.36 & 1.48 & 0.04 & 0.06 & 0.21 & 0.47 \\
\hline Co Miyun & 503.90 & 18.61 & 0.12 & 2.82 & 3.08 & 5.29 & 6.84 & 0.32 & 1.32 & 1.67 & 0.04 & 0.07 & 0.28 & 0.43 \\
\hline Co Yanqing & 158.23 & -0.85 & 0.12 & 2.14 & 1.95 & 2.62 & 3.24 & 0.26 & 1.10 & 1.27 & 0.04 & 0.07 & 0.30 & 0.39 \\
\hline
\end{tabular}

Note: Meanings of codes in Table V: $\mathrm{y}$-total enterprise income in secondary industry; $\mathrm{x}_{1}-\mathrm{x}_{13}$ hierarchical structure of employees, $\mathrm{x}_{1}$-postgraduates or above, $\mathrm{x}_{2}$-bachelor's degree, $\mathrm{x}_{3}$-college diploma, $\mathrm{x}_{4}$-senior middle schooling, $\mathrm{x}_{5}$-junior middle schooling or below; $\mathrm{x}_{6}$-senior technical title, $\mathrm{X}_{7}$-medium technical title, $\mathrm{X}_{8}$-junior technical title; $\mathrm{X}_{9}$-senior technician, $\mathrm{X}_{10}$-technician, $\mathrm{X}_{11}$-senior worker, $\mathrm{X}_{12}$-medium worker, $\mathrm{X}_{13}$-junior worker.

Appendix 6. Evaluation matrix for talent effectiveness of secondary and tertiary industries in Beijing (Unit: Million CNY/Person)

\begin{tabular}{lccccccccccccc}
\hline Areas & $\mathrm{x}_{1}{ }^{*}$ & $\mathrm{x}_{2}{ }^{*}$ & $\mathrm{x}_{3}{ }^{*}$ & $\mathrm{x}_{4}{ }^{*}$ & $\mathrm{x}_{5}{ }^{*}$ & $\mathrm{x}_{6}{ }^{*}$ & $\mathrm{x}_{7}{ }^{*}$ & $\mathrm{x}_{8}{ }^{*}$ & $\mathrm{x}_{9}{ }^{*}$ & $\mathrm{x}_{10}{ }^{*}$ & $\mathrm{x}_{11}{ }^{*}$ & $\mathrm{x}_{12}{ }^{*}$ & $\mathrm{x}_{13}{ }^{*}$ \\
\hline Dongcheng Dis. & 10.94 & 2.48 & 3.01 & 2.53 & 4.80 & 15.51 & 7.96 & 7.29 & 217.53 & 96.99 & 22.33 & 16.35 & 18.72 \\
Xicheng Dis. & 16.58 & 4.99 & 6.31 & 6.34 & 10.41 & 23.04 & 13.43 & 12.05 & 387.60 & 166.76 & 43.70 & 46.28 & 36.22 \\
Chaoyang Dis. & 13.58 & 3.05 & 3.80 & 3.06 & 4.83 & 22.16 & 11.50 & 10.85 & 256.53 & 122.51 & 41.76 & 28.55 & 23.24 \\
Fengtai Dis. & 15.63 & 2.86 & 2.46 & 1.14 & 1.25 & 13.64 & 5.94 & 4.54 & 147.50 & 58.44 & 8.00 & 5.06 & 6.12 \\
Shijingshan Dis. & 18.51 & 3.28 & 3.37 & 1.94 & 2.87 & 16.43 & 7.48 & 6.66 & 226.39 & 57.94 & 10.34 & 10.37 & 11.80 \\
Haidian Dis. & 8.67 & 2.81 & 4.08 & 3.64 & 5.93 & 13.10 & 7.77 & 8.84 & 175.06 & 76.54 & 14.35 & 33.42 & 35.10 \\
Fangshan Dis. & 41.06 & 3.89 & 3.90 & 2.72 & 1.94 & 26.67 & 7.49 & 6.43 & 215.83 & 80.21 & 19.28 & 15.06 & 14.84 \\
Tongzhou Dis. & 27.21 & 2.89 & 2.42 & 1.41 & 1.16 & 19.19 & 5.68 & 4.29 & 133.21 & 52.97 & 19.37 & 8.60 & 4.98 \\
Shunyi Dis. & 43.27 & 4.05 & 3.26 & 2.23 & 2.35 & 49.69 & 13.70 & 10.17 & 215.13 & 159.62 & 63.18 & 23.62 & 16.55 \\
Changping Dis. & 9.85 & 2.13 & 2.07 & 1.43 & 1.37 & 11.14 & 4.97 & 4.16 & 109.64 & 60.81 & 19.50 & 10.47 & 7.30 \\
Daxing Dis. & 17.54 & 2.22 & 1.99 & 1.09 & 1.09 & 13.94 & 4.96 & 3.91 & 102.22 & 48.31 & 20.14 & 10.05 & 7.11 \\
Development Zone & 31.82 & 6.82 & 8.10 & 4.81 & 13.21 & 62.44 & 30.90 & 23.67 & 461.75 & 218.82 & 56.13 & 58.29 & 75.41 \\
Mentougou Dis. & 16.87 & 1.40 & 1.14 & 0.77 & 0.66 & 11.43 & 2.88 & 2.33 & 134.78 & 44.38 & 7.60 & 7.03 & 1.98 \\
Huairou Dis. & 34.34 & 2.19 & 2.30 & 1.13 & 1.29 & 18.02 & 4.49 & 3.70 & 240.92 & 111.26 & 17.08 & 14.76 & 8.46 \\
Pinggu Dis. & 20.08 & 1.67 & 1.84 & 0.99 & 1.00 & 11.00 & 3.43 & 3.15 & 116.46 & 74.72 & 22.77 & 9.85 & 7.34 \\
Co Miyun & 43.70 & 1.79 & 1.63 & 0.95 & 0.74 & 15.56 & 3.81 & 3.02 & 140.75 & 68.37 & 18.26 & 11.79 & 6.84 \\
Co Yanqing & 13.23 & 0.74 & 0.81 & 0.60 & 0.49 & 6.04 & 1.44 & 1.25 & 37.41 & 23.20 & 5.27 & 4.08 & 3.76 \\
\hline
\end{tabular}

Note: In Table VI, $\mathrm{x}_{1}{ }^{*}-\mathrm{x}_{13}{ }^{*}$ indicate Talent Effectiveness Index in Secondary and Tertiary Industries (positive index). 